\title{
Review
}

\section{Diabetes and gender}

\author{
E.A.M. Gale, K.M. Gillespie \\ Diabetes and Metabolism, Division of Medicine, University of Bristol, UK
}

\section{Abstract}

It is often assumed that there is little or no sex bias within either Type I (insulin-dependent) or Type II (non-insulin-dependent) diabetes mellitus. This review considers evidence that sex effects of interest and importance are present in both forms of the disease. Type I diabetes is the only major organ-specific autoimmune disorder not to show a strong female bias. The overall sex ratio is roughly equal in children diagnosed under the age of 15 but while populations with the highest incidence all show male excess, the lowest risk populations studied, mostly of non-European origin, characteristically show a female bias. In contrast, male excess is a consistent finding in populations of European origin aged 15-40 years, with an approximate 3:2 male:female ratio. This ratio has remained constant in young adults over two or three generations in some populations. Further, fathers with Type I diabetes are more likely than affected mothers to transmit the condition to their offspring. Women of childbearing age are therefore less likely to develop Type I diabetes, and - should this occur are less likely to transmit it to their offspring. Type II diabetes showed a pronounced female excess in the first half of the last century but is now equally prevalent among men and women in most populations, with some evidence of male preponderance in early middle age. Men seem more susceptible than women to the consequences of indolence and obesity, possibly due to differences in insulin sensitivity and regional fat deposition. Women are, however, more likely to transmit Type II diabetes to their offspring. Understanding these experiments of nature might suggest ways of influencing the early course of both forms of the disease. [Diabetologia (2001) 44: 3-15]

Keywords Type I diabetes, Type II diabetes, sex, pregnancy, obesity.

\section{Autoimmune diabetes and sex}

Sex bias is characteristic of autoimmune disease. It has been estimated that 6.7 million women are affected by autoimmune diseases in the United States, as against 1.8 million men. The six most prevalent conditions (vitiligo excepted), accounting for $93 \%$ of

Corresponding author: E.A.M. Gale, Diabetes and Metabolism, Medical School Unit, Southmead Hospital, Bristol BS10 $5 \mathrm{NB}, \mathrm{UK}$

Abbreviations: NOD, Non-obese diabetic; LADA, latent autoimmune diabetes of adults; Th, T helper; RA, rheumatoid arthritis; MS, multiple sclerosis; TRD, transmission ratio distortion. the total, are hyperthyroidism, rheumatoid arthritis, thyroiditis, Type I (insulin-dependent) diabetes mellitus, pernicious anaemia and multiple sclerosis [1]. The estimated percentage of females affected by each condition is given in Table 1 [2]. Type I diabetes stands apart from the other conditions listed by virtue of its early age of onset and lack of female predominance, but it should be noted that the data in Table 1 were derived only from studies in children.

Most reviews have concluded that male sex bias in Type I diabetes is absent [3] or minor [2]. We will present evidence that some populations show male sex bias from birth, and that all populations studied show male excess in early adult life. We examine the older literature to explore the hypothesis that males 
Table 1. The sex distribution of common autoimmune diseases

\begin{tabular}{lcl}
\hline Condition & Peak onset (year) & $\%$ females \\
\hline Type I diabetes & $2-15$ & $45 \%$ \\
Multiple sclerosis & $20-35$ & $60 \%$ \\
Rheumatoid arthritis & $20-40$ & $65 \%$ \\
Hashimoto's thyroiditis & $30-50$ & $85 \%$ \\
Thyrotoxicosis & $30-50$ & $85 \%$ \\
Pernicious anaemia & $40-80$ & $60 \%$ \\
\hline
\end{tabular}

Note that data for diabetes were drawn from studies with onset in childhood. Modified from Beeson [2]

are preferentially targeted by environmental factors associated with the rising incidence of the disease. We review the effects of the hormonal changes of puberty and pregnancy upon diabetes progression in other autoimmune diseases and in diabetes, and discuss sex differences in transmission of the disease from affected parents. Finally, we review possible genetic mechanisms for a sex bias in autoimmune diabetes. These findings in humans contrast with findings in the non-obese diabetic (NOD) mouse, our prime model of diabetes autoimmunity, in which diabetes progression is almost twice as common in females [4].

\section{The phenotype of autoimmune diabetes changes with age}

Type I diabetes is mediated by autoimmune processes that result in insulin deficiency. There is increasing recognition that the rate of beta-cell destruction can be highly variable, typically rapid in young children but slower in adults [5]. The epidemiology of childhood diabetes is relatively simple to study, because children with diabetes have a distinctive phenotype, are highly visible within the health care system and in western societies almost always have the autoimmune form of the disease. Such children have a characteristic pattern of HLA susceptibility (with important qualitative differences between populations) and of circulating islet autoantibodies.

The phenotype of autoimmune diabetes in later life is much less distinctive. The disease presents along a spectrum of insulin deficiency, HLA type and islet autoantibodies. All these features are less pronounced in adults who present with classic Type I diabetes than in children [6] and can sometimes be absent [7]. In older age groups the disease seems to blur almost imperceptibly into the larger mass of middle-aged and elderly patients with non-immune diabetes. Older patients with glutamic acid decarboxylase (GAD) autoantibodies exceeding 5 RU have an earlier requirement for insulin and differ in phenotype from Type II (non-insulin-dependent) diabetes mellitus, with fewer features of the metabolic syndrome. A spectrum is however apparent even within the subgroup of patients with GAD antibodies, such that those with higher titres are more likely to carry markers of HLA susceptibility [8]. The term "latent autoimmune diabetes of adults" (LADA) has been coined for this group [9] but lack of clear phenotypic characterization remains a major obstacle to epidemiological analysis. Relatively little is therefore known concerning the true incidence and natural history of autoimmune diabetes in later life, although a Danish study has suggested that $44 \%$ of all cases of clinically defined Type I diabetes present over the age of 40 years and that lifetime risk is as high as $1.5 \%$ in their population [10]. Statements about the sex incidence of Type I diabetes can therefore be made with considerable confidence in childhood diabetes, with rather less confidence in young adults, and no firm conclusions are possible over the age of 50 years. In the following sections we will consider evidence of a sex bias in each of these age groups.

The under-15s. A careful review of sex differences in children presenting under the age of 15 identified a minor male excess in Europe and populations of European origin, with a female excess in populations of African or Asian origin [11]. European countries with a male excess include Sardinia, mainland Italy, the United Kingdom, Norway, Sweden and Finland. Denmark, France and the Netherlands have approximately equal rates and the Baltic and Slav countries generally show a female preponderance. There is a weak association between male sex and high frequency of diabetes. More striking is the observation that all populations with an incidence higher than 23/100000 had a male excess, whereas all those with a rate below 4.5/100000 had a female excess. The reason for these differences is not known.

Early adult life. Although the incidence of childhood diabetes has been extensively studied, relatively little information is available concerning the incidence of autoimmune diabetes in adult life. We have noted that with increasing age the phenotype becomes increasingly hard to distinguish from the syndrome of Type II diabetes. A number of studies are however available in which the definition of Type I diabetes in early adult life is based on requirement for insulin [12-22] (Table 2). These are remarkably consistent in showing a male preponderance for new cases diagnosed over the age of 14 years, with a male:female ratio ranging from 1.3-2.15. This can be seen in countries characterised by male preponderance from birth, such as Sweden and Norway, but is also prominent in countries such as Belgium, in which the male:female ratio approximates to 1.1 up to age 14, but rises to 1.7 above that age [16]. Swedish data also show a striking divergence in the sex ratio over the age of puberty (Fig. 1) [18]. The one published study which seems to run counter to this trend comes from Kuwait, which shows a female preponderance in 
Table 2. Sex distribution in adult onset Type I diabetes

\begin{tabular}{lllll}
\hline Country/town [ref] & Period & Age range & $n$ (male) & male/female \\
\hline Belgium [16] & $1989-1995$ & $15-39$ & $885(552)$ & 1.66 \\
Denmark [17] & $1970-1976$ & $15-30$ & not stated & 1.50 \\
Denmark [12] & 1973 & $15-30$ & not stated & 1.32 \\
Minnesota [20] & $1945-1969$ & $0-29$ & not stated & 1.30 \\
Norway [22] & $1956-1964$ & $15-19$ & not stated & 1.55 \\
& & $20-24$ & not stated & 1.30 \\
Norway [21] & & $25-29$ & $784(446)$ & 1.15 \\
Sweden [13] & $1978-1982$ & $15-29$ & $1934(1214)$ & 1.32 \\
Turin [14] & $1983-1987$ & $15-34$ & $160(97)$ & 1.69 \\
Wisconsin [19] & $1984-1988$ & $15-29$ & $102(60)$ & 1.83 \\
Zagreb [15] & $1970-1979$ & $15-29$ & $145(82)$ & 1.43 \\
\hline
\end{tabular}

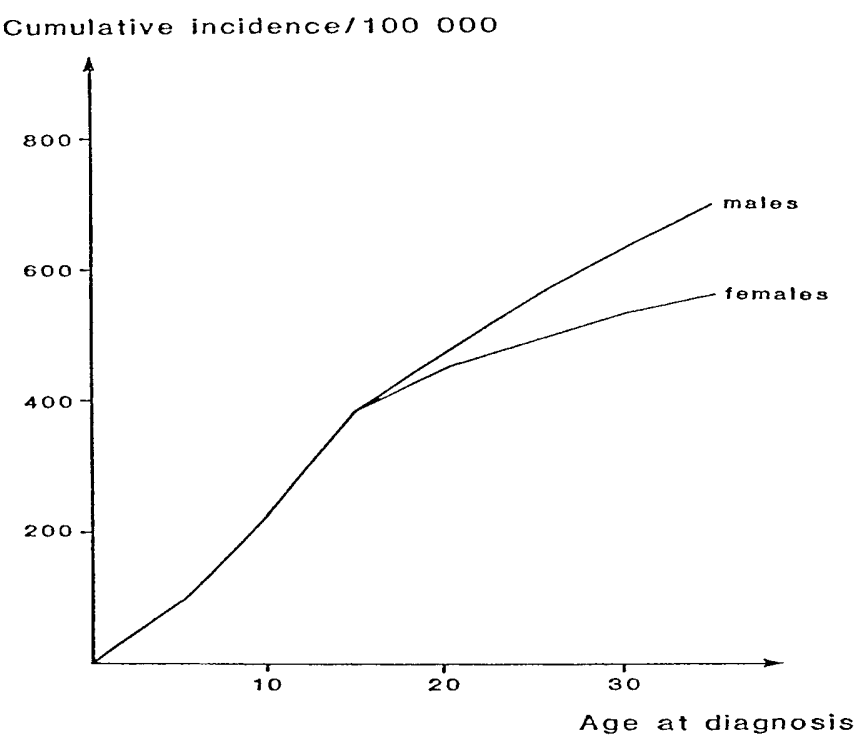

Fig. 1. Cumulative incidence/100000 of Type I diabetes over the age range 0-34 years in Sweden 1983-1987. Males are more commonly affected than females after the age of puberty. From Nystrom et al. [18], with permission

young adult life, but closer analysis of this paper shows that many cases were not insulin-treated and that women with gestational diabetes were also included [23].

Population-based family studies also show evidence of male excess in early adult life. In the Pittsburgh Study of siblings of children diagnosed under the age of 17 years, secondary attack rates were equal up to the age of 15 but males were more commonly affected after that age. By the age of 30 overall secondary attack rates were $7.0 \%$ for males and $5.5 \%$ for females, although this difference did not reach statistical significance [24]. A similar phenomenon has been observed in the Bart's-Oxford Family Study (unpublished data). Therefore to date, and on the basis of limited data, Type I diabetes seems to show a clear male preponderance in all populations of European origin studied in early adult life. This excess persists up to age 40 in some populations; over this age phenotypic characterisation of diabetes becomes more of a problem. No difference in sex emerges from a Danish study of insulin prescriptions for individuals with diabetes onset over the age of 50 years [12].

Other groups of patients deserve brief consideration at this point. A group of "polyendocrine" patients has been described in whom islet cell antibodies (ICA) are associated with clinical or subclinical thyroid or other autoimmune conditions. This group shows a preponderance of middle-aged females [25]. This could however be because patients were identified by a large clinic specialising in thyroid autoimmunity, a condition with a heavy female bias.

A second group of interest contains patients presenting in early to middle life without markers of autoimmune diabetes. An early study of patients with newly diagnosed diabetes aged 18-50 years from the United Kingdom classified 87 out of 254 as having Type I diabetes on clinical grounds but found an overall male sex bias (151 male vs 103 female) across both groups [26]. Equally, a Danish study of 1240 patients diagnosed over the age of 30 years and with a short or long-term requirement for insulin shows that about twice as many males as females were diagnosed in the age range 40-60 years but makes no comment on this observation [10]. Immunogenetic characterisation of newly diagnosed patients referred to the Belgian Diabetes Registry identified a subgroup of 408 (25.9\%) in the 15 to 40 -year age group who tested negative for islet autoantibodies. In this group the male:female ratio was 1.8 , as against 1.5 in those with detectable antibodies [27]. This unexpected finding is consistent with a report from Sweden in which immune markers were examined in 203 consecutively diagnosed patients aged $40-54$ years. A striking male preponderance (2.2:1) was noted in this group in which only 19 
Table 3. Secular change in the sex ratio of patients attending a clinic in the United Kingdom 1930 to 1963

\begin{tabular}{lllll}
\hline Year & \multicolumn{4}{l}{ Age at diagnosis (years) } \\
\cline { 2 - 5 } & $20-34$ & $35-49$ & $50-64$ & $65-79$ \\
\hline $1930-1934$ & 1.07 & 0.59 & 0.51 & 0.5 \\
$1935-1939$ & 1.60 & 0.69 & 0.31 & 0.54 \\
$1940-1944$ & 1.57 & 0.72 & 0.46 & 0.69 \\
$1945-1949$ & 1.54 & 0.65 & 0.44 & 0.38 \\
$1950-1954$ & 1.80 & 0.96 & 0.59 & 0.59 \\
$1955-1959$ & 1.75 & 1.47 & 0.86 & 0.74 \\
$1960-1963$ & 1.13 & 1.78 & 0.96 & 0.78 \\
\hline
\end{tabular}

Data from Malins et al. [31]

(9.4\% ) were judged to have Type I diabetes [28]. In a later section we will see that there has been an historical shift from female to male predominance in patients in this age group and a possible explanation will be suggested in the discussion.

\section{Is male preponderance in young adults with diabetes a new phenomenon?}

The incidence of childhood diabetes has risen steadily in Europe and other parts of the world over the past 30-50 years [29] and the highest rates of childhood onset disease are found in countries with an excess of affected males [11]. This raises the possibility of a preferential interaction between the environment and male sex. We therefore examined the older literature for clues as to whether male predominance is a recent or longstanding characteristic of Type I diabetes.

The United States Public Health Survey of 1935-1936 found no evidence of a sex bias in children and mild female preponderance in young adults. Since ascertainment of diabetes was based on direct questioning and did not distinguish the form of treatment offered, it is possible that sex differences in the younger adult age groups were biased by gestational diabetes. United States data are therefore limited by lack of information concerning insulin treatment but on face value suggest a moderate female excess in young adults in the 1930s [30].

In contrast, clinic-based data from the United Kingdom suggest that male excess has been a constant feature of diabetes in early adult life (Table 3 ). Here again, treatment is not specified and the figures should be viewed with caution but this study does suggest a relatively constant male excess for the age group 20-34 years over the period from 1935-1960 [31].

The best data, however, come from Norway, a country that currently shows a clear male excess in diabetes in childhood and early adult life. A study published in 1927 examined mortality statistics for the years before the introduction of insulin and found
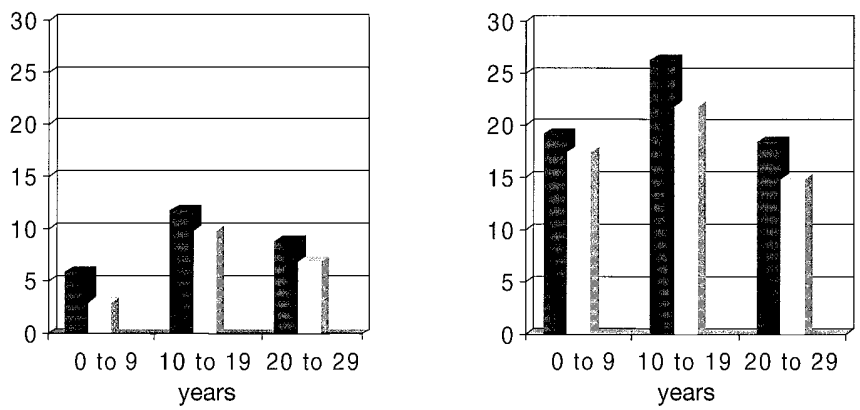

Fig. 2. Incidence/100 000 and sex in Norway. Males are shown in black. The panel on the left shows data from Westlund [33] for the period 1925-1954, compared with data from Joner and Sovik [21] for the period 1978-1982. Ascertainment could have been incomplete in the earlier study. Male sex bias can be shown over a 50-year time period in Norway

that more males than females were recorded as dying from diabetes for all ages up to 50 years [32]. Hospital admissions data for Oslo for the period 1925-1954 showed a consistent male bias in children and young adults [33] virtually identical to that found in more recent studies [21] (Fig. 2). We can conclude that male excess in early onset diabetes is an inherent characteristic of some populations at least and that in Norway the ratio between the sexes has not changed over a period in which the recorded incidence of the disease has risen rapidly.

\section{Immune factors, sex and autoimmunity}

We have presented evidence that in western societies there is a male bias in autoimmune (and possibly also in non-autoimmune) diabetes diagnosed over the age range corresponding to female childbearing life. This observation runs counter to experience in all other major cell-mediated autoimmune disorders. We will therefore pause to consider the influence of sex-related factors upon the immune system and the progression of autoimmune disease in general.

It has long been recognised that sex influences the behaviour of the immune system. Studies in mice demonstrate that immune responses tend to be more vigorous in females [34], an observation that might explain the increased incidence of autoimmune disease in females in animal models of autoimmunity [35]. The evidence for sex differences in the human immune response is less convincing but circulating $\operatorname{IgM}$ (but not $\mathrm{IgG}$ ) concentrations are higher in women [36], whereas men have lower $\mathrm{CD}^{+}$counts and therefore a lower CD4/CD8 T-cell ratio than women [37].

It not always appreciated that our knowledge of autoimmunity in animal models is derived almost exclusively from studies in female mice. Mouse models of autoimmune diseases such as rheumatoid arthritis, multiple sclerosis and autoimmune diabetes all show 
a strong sex bias. For example, in the inbred parental strain of the NOD mouse $90 \%$ of females are affected as against $50 \%$ of males [4]. Sex bias in these models is still largely unexplained but there is considerable evidence that oestrogens enhance and androgens protect against autoimmune disease.

Oestrogens influence the growth and differentiation of many tissues and act upon the maternal immune system to prevent rejection of the fetus during pregnancy. The effects of these hormones could be mediated by the hypothalmo-pituitary axis [38] but oestrogen receptors are present on antigen presenting cells including macrophages [39] and receptors for both androgens and oestrogens are present on on $\mathrm{CD}^{+}$[40] and $\mathrm{CD}^{+}{ }^{+} \mathrm{T}$ cells [41]. This suggests that sex hormones interact directly with immunocompetent cells to modulate the immune response [42]. Studies in the mouse show that enhanced expression of T helper 1 (Th1) cytokines (IFN $\gamma, \mathrm{TNF} \alpha$ ) is associated with cell-mediated immune responses, whereas enhanced expression of T helper 2 (Th2) cytokines (IL4, IL5, IL10) promotes humoral immune reponses. In these models oestrogens seem to modify the Th1/Th2 equipoise in a dose-dependent fashion, such that low concentrations can stimulate whereas high ones inhibit specific immune responses. These observations might help to explain why women are more prone to develop a number of autoimmune diseases between menarche and menopause, some of which show striking clinical remission in the course of pregnancy [43].

Conversely, there is strong evidence from mouse models that androgens are protective against autoimmune disease. Castration of males increases the incidence of diabetes and of experimental allergic encephalomyelitis in the corresponding models [44-46], and testosterone treatment of NOD females can prevent islet destruction [47]. The protective effect of testosterone is mediated by the induction of a $\mathrm{Th} 2$ bias in autoantigen-specific $\mathrm{T}$ lymphocytes [48]. Extrapolation from mouse to man should however be cautious because the Th1/Th2 paradigm might have limited relevance in humans, in whom immune responses are much less polarised than in the mouse [49].

\section{Effects of pregnancy and hormone substitution in other autoimmune conditions}

In pregnancy the cellular immune responses of the mother are down-regulated to prevent immunity directed against the fetus [50] and the effect of pregnancy upon autoimmune diseases has therefore attracted considerable interest. The maternal immune system recognises fetal histocompatibility antigens derived from the father and mounts an immune reponse against them [51]. The $\mathrm{B}$ cell response is sig- nalled by the appearance of circulating antibodies and maternal sera played a major role in early investigation of the HLA system in humans [52]. T-cell recognition of paternal alloantigens has also been shown in a transgenic mouse model and a transient state of T-cell tolerance specific for paternal alloantigens has been found [53]. One clinical report has suggested that remissions are more likely to occur in patients with rheumatoid arthritis when there is disparity between maternal HLA class II alleles and the paternal alleles carried by the fetus, especially when the disparity exists at the DQ locus [54].

Sex issues have attracted particular attention in two human autoimmune diseases, rheumatoid arthritis (RA) and multiple sclerosis (MS). A task force report on sex, multiple sclerosis and immunity ([43], www.sciencemag.org/feature/data/983519.shl) offers a useful review of these areas. Both conditions will be considered briefly before we go on to examine autoimmune diabetes. In RA the sex ratio is 3-4:1 during childbearing years, but disease incidence rises sharply in both sexes after the age of 50 and the sex ratio tends to narrow in later life. In MS the sex ratio is 2-3:1 and female preponderance is also more pronounced in childbearing years. Women tend to develop MS earlier, but in a milder form; disease progression is typically more aggressive in men.

In 1938 Philip Hench reported that rheumatoid arthritis showed remission in pregnancy [55], an observation that stimulated his search for an endogenous substance - which he termed "substance X" - that could relieve the symptoms of arthritis [56]. This quest led to the finding that arthritis could be relieved by cortisone and the award of a Nobel prize, although ironically endogenous cortisol is no longer considered responsible for remission of RA in pregnancy. Later studies confirmed that some $75 \%$ of patients report relief of symptoms during pregnancy, whereas almost all relapse in the immediate post-partum period [57]. Multiple sclerosis also remits in pregnancy, with a $70 \%$ reduction in the frequency of relapse in the third trimester, and a corresponding rebound to $70 \%$ above baseline in the 3 months post-partum [58]. In contrast, systemic lupus erythematosus, a condition in which humoral rather than cellular immune responses predominate, frequently shows flares in the course of pregnancy [59].

Oral contraceptives appear to protect against the development of rheumatoid arthritis [60], and one case-control study found that a nulliparous woman not using the oral contraceptive pill before the age of 35 had a fourfold increase in the subsequent risk of rheumatoid arthritis [61]. These findings remain somewhat controversial [62].

Many therapies have been tried in an attempt to reproduce the benefits of pregnancy in patients with rheumatoid arthritis, but with very limited success [63]. We have seen that oestrogens and androgens 


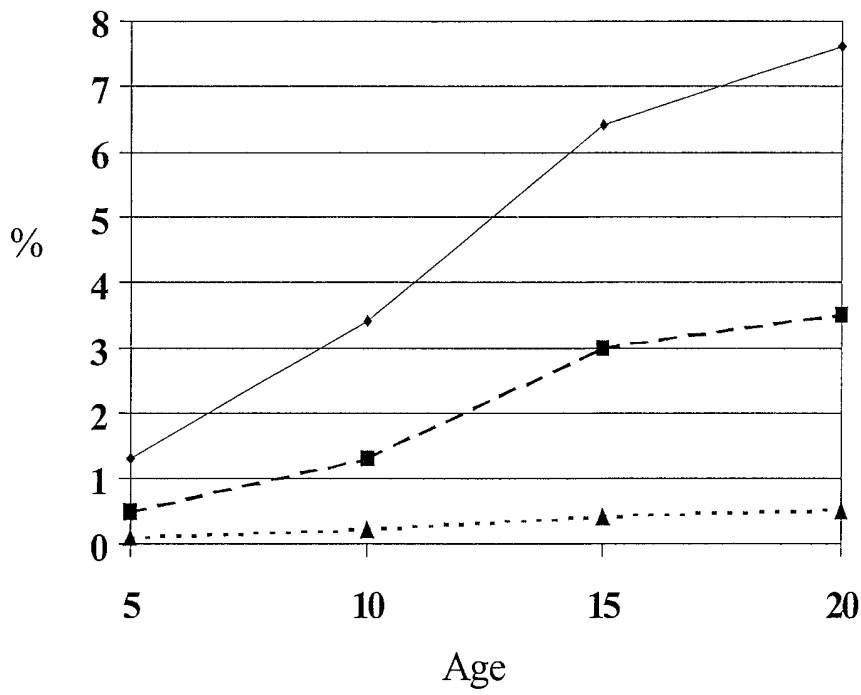

Fig. 3. Risk of Type I diabetes in offspring of affected fathers $(-)$, affected mothers $(--)$, and in the general population of Finland (-- - -). From Tuomilehto et al. [72], with permission.

modulate disease progression in animal models of autoimmunity but sex hormones have proved relatively ineffective in human disease and have found no established place in prevention or therapy of RA and MS.

\section{Puberty, pregnancy and contraception in diabetes}

Type I diabetes typically reaches peak incidence around the time of puberty but it is not clear whether diabetes is precipitated directly by the hormonal changes associated with this transition or is due to the considerable increase in insulin resistance that occurs at the same time [64]. Insulin resistance would however provide sufficient explanation. Islet autoimmunity is a chronic smouldering process initiated very early in life and the endocrine and metabolic changes of puberty might well be expected to uncover pre-existing islet insufficiency and hence precipitate the disease. Type I diabetes is also more likely to present in pregnancy than in the non-pregnant state but here again it is difficult to distinguish between the effects of the immunological and metabolic adaptation to pregnancy. As in puberty, the metabolic challenge of pregnancy could well be sufficient to precipitate diabetes in people with subclinical beta-cell loss. A longitudinal study of insulin-requiring diabetes acquired in pregnancy found that the rate of Type I diabetes in pregnancy was $70 \%$ higher than in non-pregnant women of that age in the background population [65]. Of the 46 women in this group, $92 \%$ had HLA-DR3 or DR4 or both compared with $57 \%$ of a control group. Consistent with the explanation that diabetes was precipitated by the metabolic stress of pregnancy, 37 of the women went into prolonged non-insulin requiring remission after delivery [66].

It is therefore not possible at present to draw useful conclusions as to the influence of pregnancy, the prime test of a sex-related autoimmune condition, upon progression of autoimmune diabetes. Equally, the effect of contraceptive use and parity upon progression to an autoimmune form of diabetes is not known, although it can be noted that the relative risk of progression to any form of diabetes is slightly reduced - although not significantly so - in women taking the contraceptive pill [67].

\section{Transmission of Type I diabetes}

Further evidence of sex-related effects come from studies of transmission of diabetes from one generation to the next. Studies from the United States [68-71], Finland [72] and Denmark [73] have shown that fathers with Type I diabetes are more likely than affected mothers to transmit diabetes to their offspring (Fig. 3). The studies are consistent in showing that the risk of childhood-onset diabetes in the offspring of an affected father is two to three times greater than that of the offspring of an affected mother. Equally, islet autoantibodies are more commonly found in the offspring of diabetic fathers than diabetic mothers [74].

The Finnish study, which was considerably larger than the others, suggests that the incidence of diabetes is rising more rapidly in the offspring of people with diabetes than in the general population. It also shows that fathers are more likely to transmit diabetes to their daughters and mothers to their sons [72]. This observation was confirmed by the EURODIAB group for father/daughter transmission but not for increased transmission from mothers to sons [75]. Preferential cross-sex transmission could therefore be a reality but the effect is relatively weak and further confirmation is needed. Conflicting results are reported from this and other studies of parents with diabetes concerning the effect of birth order and parental age at delivery, but early onset diabetes in the parent does appear to increase risk of diabetes in the child $[71,73]$.

The key point at issue is not however in doubt; diabetic fathers transmit greater risk to their children than do diabetic mothers. Why should this be? There is no evidence to support selective loss of fetuses bearing diabetes susceptibility genes [69]. Because the risk conferred by an affected father is of the same order as that conferred by having an affected sibling, maternal diabetes might in some way be protective and three broad lines of explanation therefore remain open.

The first possibility is that fetal beta-cell development is accelerated by the hyperglycaemic environ- 
ment of a diabetic pregnancy, as shown in post-mortem studies of infants of diabetic mothers [76] and that this reduces subsequent liability to autoimmune damage. Consistent with this, glucose infusion plus treatment with glucagon or arginine for the first 6 days after birth considerably reduces the risk of diabetes in neonatal BB rats [77]. The experiment of nature that could confirm this in human diabetes would be that children born to mothers who develop Type I diabetes after pregnancy have a higher risk of diabetes than those born to mothers who already have diabetes. The Danish group found that the protective effect of maternal diabetes was apparently lost in children born to mothers before the diagnosis of diabetes, but their observation was based on only 14 diabetic offspring [73]. This issue therefore is still unresolved.

A second possible explanation is that protection is in some way due to maternal effects upon ontogeny of the immune system in the fetus, resulting in tolerance induction [69]. It is not clear what mechanism might be responsible for this postulated effect but the risk of diabetes in the offspring of non-diabetic mothers is modulated by maternal age; a mother giving birth over the age of 40 is up to 3 times more likely to have a child who develops diabetes than a mother in her twenties [78]. This observation suggests that the intrauterine environment exerts a major influence upon subsequent risk of diabetes in the child in the absence of maternal hyperglycaemia. Type I diabetes, like Type II diabetes [79], therefore shows evidence of fetal origins.

A third possibility is that affected fathers transmit an excess of susceptibility genes to their offspring. The Mendelian expectation is that each of the two alleles present in a parent would have an equal chance of being transmitted to the offspring. There is however evidence that in some situations the expected 50:50 transmission ratio does not apply, a phenomenon referred to as transmission ratio distortion (TRD). Evidence for this has proved controversial in humans but there is evidence of TRD at the INS-IGF2 VNTR such that class I alleles have an approximate 55\% probability of transmission [80]. The class I allele is associated with suceptibility to Type I diabetes and the class III allele with protection. Complex effects have been reported. For example, a certain class I allele does not predispose to diabetes if transmitted by a father with an untransmitted class III allele [81]. The effect of this gene upon diabetes susceptibility is however relatively weak, and on present evidence it might contribute to, but not explain, the differential risk conferred by fathers and mothers. Transmission ratio distortion within the HLA region might be expected to have a more powerful influence and it has been suggested that differential parental transmission of an HLA-DR4-linked diabetes susceptibility allele might be responsible for the differential risk in off- spring [82]. It was subsequently pointed out that selection for families with an affected child will inevitably bias the sample in the direction of apparent TRD [83] and appropriately controlled studies have yet to show evidence of TRD for HLA class II alleles conferring susceptibility to Type I diabetes [84].

\section{Genetic factors and sex in Type I diabetes}

We have observed in this review that some populations show a male preponderance of childhood diabetes from birth but others do not. In Norway the sex ratio has remained constant over 50 years, although the incidence of diabetes has risen rapidly over the same time. The children of fathers with Type I diabetes are more likely to develop diabetes than those of mothers with Type I diabetes and fathers are rather more likely to transmit diabetes to their daughters. All these observations would be consistent with a genetic explanation. How then could genes influence the sex in which diabetes is expressed?

As in other autoimmune disorders, the HLA region plays the major part in determining genetic susceptibility to Type I diabetes and in most populations of European extraction over $90 \%$ of affected people carry HLA DRB1*03 or HLA DRB1*04. There are similar and overlapping HLA associations in most forms of autoimmune disease and the common disorders are polygenic, with a major contribution from the HLA region. Type I diabetes shows linkage to the HLA region (IDDM1) and the insulin gene region (IDDM2) as well as to a number of other less well characterised loci. Candidate non-HLA loci for diabetes and other autoimmune disease co-localize, suggesting a shared common underlying susceptibility to autoaggression. On this hypothesis, some genes are common to autoimmune disorders and other genes are responsible for vectoring the immune system towards specific target tissues [85].

The strong association of thyroid autoimmunity with female sex has suggested a role for genes on the $\mathrm{X}$ chromosome and linkage between Graves' disease and a locus on chromosome Xq21.33-22 has been found [86]. Multiple sclerosis and rheumatoid arthritis have also been linked to the $\mathrm{X}$ chromosome, in this case locus Xp11 [87, 88]. Genetic analysis of experimental autoimmune encephalomyelitis, an animal model of multiple sclerosis, also provided evidence for a locus on mouse chromosome X, homologous to human Xq13-q22 [89]. There is therefore mounting evidence that genes on the short arm of the $\mathrm{X}$ chromosome contribute to susceptibility to some autoimmune conditions.

The products of genes on different chromosomes possibly interact to increase disease susceptibility in the absence of any physical link between transmission of these genes. In Type I diabetes a survey of pa- 
Sex and diabetes

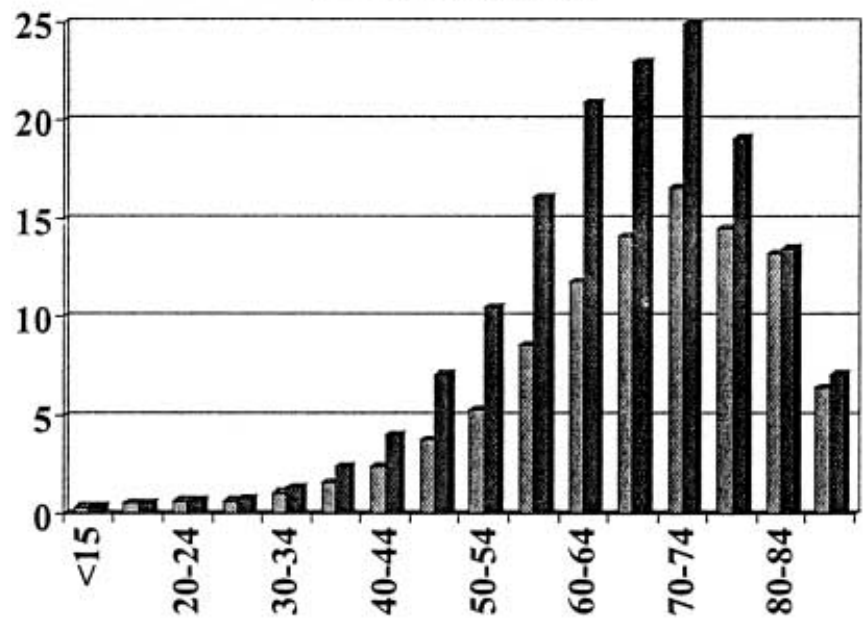

Fig. 4. Prevalence of diabetes by sex and age of onset in a US clinic in 1933. The female excess in late onset diabetes characteristic of the first half of the last century is shown ( $\square$ males, females). Drawn from data in Pincus et al. [92].

tients from the United States, United Kingdom and Sardinia found that there was a pronounced overall male sex bias in patients with DR3/X (where $X$ was not DR4). In patients with DR3/X the sex incidence was 1.7 , as against 1.0 in DR4/X (where $\mathrm{X}$ was not DR3) or 1.2 in DR3/4. The effect was mostly strongly evident in the Sardinian population [90]. Further, there was evidence of linkage to the candidate locus Xp13-p11, in a region already implicated in multiple sclerosis and rheumatoid arthritis. A reported deviation from the expected Mendelian 1:1 ratio of grandpaternal/grandmaternal alleles at Xp11.4-p21.1 suggested the presence of a TRD locus in this region [91]. Further analysis established that the TRD locus does not influence linkage of Type I diabetes at Xp11.4-p21.1 [92]. Being male and DR3 positive is therefore a high risk phenotype, at least in Sardinia [90]. The findings of the Sardinian group could not however be reproduced by analysis of the Belgian Registry, in which the male:female ratio is 1.5 after age 15 , and in which there was no evidence of interaction between DR3 and an X-linked factor [27]. The $\mathrm{X}$-linked susceptibility might contribute to risk in some populations but not in others.

\section{Type II diabetes}

Type II diabetes is now considered to show no major overall sex bias [93] but few recent investigators have commented on the fact that a major sex shift occurred within late-onset diabetes in the course of the twentieth century. A pronounced female preponderance was noted in a cohort from an American clinic (Fig.4) [94] and confirmed in the United States Na- tional Health Survey of 1935-1936 [30]. This selected a sample of 2.5 million people living in 700000 households in 83 cities and found that almost twice as many women as men were affected from ages 45 to 64 . The authors comment that "Under age 25 , the rates for the two sexes are not much different; at ages 25 to 34 years, the females are higher by $20 \%$, at ages $35-44$ by almost $60 \%$, and at ages from 45 to 64 , their rates are almost double those for males". Of the estimated total number of 500000 cases in the United States, $38.5 \%$ were predicted to be male and $61.5 \%$ female [30]. A similar ratio emerged from a survey of hospital admissions in Oslo from 1925-1954 [33] and indeed almost all studies published before that mid-century show a clear female bias [95]. The males/female ratio rose considerably in all age groups over the age of 35 attending one clinic in the United Kingdom between 1930 and 1960 (Table 3). The greatest change was seen in the 35-49 age group, in which the ratio changed from 0.65 in 1945-1949 to 1.78 in 1960-1963 [31]. African Americans showed a clear female preponderance in diabetes prevalence over the years 1963-1985 but the prevalence in black males increased rapidly relative to the rate in females over this period [96].

Possible explanations for the changing sex ratio in late-onset diabetes include decreasing parity in women and a more sedentary lifestyle leading to increased obesity in men. Kelly West reviewed this question in detail and pointed out the cultural complexity of male as against female obesity in different societies [97]. To take a more recent example, the National Health and Nutrition Examination Survey, NHANES III, showed a similar prevalence of overweight men in the Non-Hispanic white and black populations over the age range $20-74$ years $(32 \%$ vs $31.8 \%$ ) whereas the equivalent rates were $32.3 \%$ for white as against $49.1 \%$ in black women [98]. Obesity has traditionally been more common in women in western societies, but West cites evidence for increasing obesity in men relative to women in the United Kingdom. His conclusion is that changes in the sex distribution of obesity are largely responsible for the rise of male diabetes [97]. Later support for his view comes from health surveys of all inhabitants of one Norwegian county, conducted in 1984-1986 and 1995-1997. In the first survey, diabetes was significantly more common in women over the age of 20 $(3.20 \%$ vs $2.62 \%)$ but only a decade later the prevalence in men had also risen to $3.20 \%$ whereas the prevalence in women was unchanged. Over the same period weight distribution in the background population showed a systematic increase, equivalent to $4 \mathrm{~kg}$ in men and $3.3 \mathrm{~kg}$ in women. The number of people aged 20-40 years with a BMI of 30 or more doubled and a sharp increase in the prevalence of diabetes was seen under age 50 in women (balanced by a decrease in older age groups) and under age 60 in males. 
At the time of the first survey $50 \%$ of those surveyed who were known to have diabetes were overweight and $30 \%$ had lean body mass; by the second survey the balance had shifted to $65 \%$ and $18 \%$, respectively [99].

\section{Discussion}

A considerable literature has accrued around the topics of sex hormones, sex and susceptibility to immune-mediated disorders, especially multiple sclerosis and rheumatoid arthritis, yet these issues are rarely considered by researchers in diabetes. This lack of interest has been based - and not unreasonably - on the observation that the overall sex balance is relatively equal. Type I diabetes is however the only major cell-mediated clinical or experimental autoimmune disorder which lacks a clear female bias, which in itself is an anomaly of some possible significance. Equally, the current balance between the sexes in late-onset diabetes conceals the remarkable sex shift that has occurred in the middle-aged population over the course of the past century. The general assumption that sex is not an issue for diabetes is to some extent self-fulfilling because it leads to a situation in which certain types of question are not asked and relevant studies are not undertaken. A further consequence is that there is no recognised body of literature on the subject. This review represents an attempt to bring together some of the elements needed for such an overview.

Any statement concerning the sex distribution of diabetes should be qualified by information concerning the nature of the cohort(s), the calendar years over which the observations were collected, the age-band studied and the criteria used to define the condition. These conditions have been adequately fulfilled for childhood-onset diabetes, and a spectrum ranging from female to male predominance has been defined. The two extremes are represented by a number of low-incidence non-European populations at the female end of the spectrum and by high-incidence populations from northern European and Sardinia at the male end. The majority of populations studied lie, however, relatively close to unity and show a weak but positive correlation between incidence and male bias [11]. It is of obvious interest to establish whether the pattern of sex distribution is intrinsic to a population, and therefore possibly genetic, or whether it can be attributed to cultural and environmental differences between populations. No clear answer is possible at this stage but we have noted that the sex ratio in children and young adults with diabetes in Norway has remained remarkably constant over a 50 year period during which the incidence of childhood diabetes has doubled. This would favour a "genetic" explanation, due for example to the contribution of genes linked to the $\mathrm{X}$ chromosome.

The next age-band examined was the approximate age-range 15-40 years. Consideration of the relatively small number of studies based on early requirement for insulin (Table 3) suggests that an approximate 3:2 male bias is characteristic of this age range, at least in the European-origin populations that were studied. Populations with a childhood male excess tend to show an exaggeration of this bias in young adult life but a similar sex effect can be seen in populations in which the ratio is approximately equal over the prepubertal period (Fig. 1). This raises the possibility that sex hormones influence the risk of developing autoimmune diabetes. If so, the oral contraceptive pill might conceivably protect against onset of Type I diabetes, which could justify further investigation.

We went on to consider sex effects in the transmission of Type I diabetes from affected parents. It has repeatedly been shown that men with Type I diabetes are two to three times more likely than affected women to transmit the disease to their offspring. Oddly, this is the mirror image of transmission of Type II diabetes, which is more commonly transmitted from an affected mother [100]. Although metabolic, immunological and genetic explanations have been proposed, the reason why the offspring of affected mothers are less susceptible to autoimmune diabetes is still not known. The metabolic hypothesis could however be tested by comparison of large numbers of mothers who developed diabetes before and after delivery. Genetic mechanisms affecting transmission of susceptibility genes might also be a factor and the finding of transmission ratio distortion in relation to a diabetes suceptibility gene is of considerable interest [80]. Even so, we lack evidence of a genetic effect sufficiently potent to explain a two- to threefold difference in risk. Finally, we have suggested that the maternal intrauterine environment has more influence than is currently believed upon future development of the fetal immune system. Indirect support for this contention comes from observation of the effect of maternal age at delivery upon subsequent risk of diabetes in the child, an effect that is possibly of the same order of magnitude as the transmission difference between affected mothers and fathers [78]. Does fetal programming of the immune system exist?

Sex effects are also present in what might be termed "grey zone" diabetes. Thus, although evidence is more scanty, pronounced male preponderance has been described in patients diagnosed with diabetes from early adult life up to the age of around 50 years who lack antibody markers of autoimmune diabetes. The temptation to label this group as having Type II diabetes is best avoided, especially if the distinction is made on the basis of the cut-off point of a GAD antibody assay applied to a single blood sam- 
ple. It might be more productive to concentrate on careful phenotypic characterisation within an undoubtedly heterogeneous group of patients. Some of these might fall within the spectrum of immune-mediated insulin-deficient diabetes, others could represent a genetic subtype of the syndrome of non-autoimmune diabetes [101] and others again are likely to have the common obesity-related form of the disease.

Hyperglycaemia develops in any form of diabetes when the secretory capacity of the pancreatic beta cell is exceeded by the metabolic demands of the rest of the body. Sex-related differences in insulin sensitivity might therefore influence disease susceptibility, regardless of aetiology. Women have a higher percentage of fat than men, but similar whole body insulin sensitivity [102]. A comparison of muscle glucose uptake in 30-year-old men and women matched for body mass and fitness showed that cardiac muscle was equally responsive to insulin in either sex, but that skeletal muscle glucose uptake was $50 \%$ greater in the women [103]. Equally, studies in a multi-racial population of normoglycaemic men and women aged 25-44 years showed that women secreted the same amount of insulin as men in response to the OGTT, despite a higher percentage of body fat. After adjustment for body fat, women were significantly more sensitive to insulin than men [104]. This "female insulin advantage" suggests that men are more likely than women to develop diabetes in response to increasing obesity. If so, the relation is not with BMI because a linear association with diabetes is shown in both sexes up to a BMI of 30 and rises more steeply in females [105]. The explanation lies rather in the predisposition of aging men to central fat deposition, associated in men (but not in women) with reduced oxidation of fat [106]. Intra-abdominal fat could be more predictive of diabetes than BMI and physical inactivity strongly influences this pattern of fat deposition [107]. Social factors have played an important part in the rise of male indolence and obesity in that many jobs done by men required heavy physical labour in the early part of the past century and travel was by foot or bicycle. Automation and the motor car could largely explain this historical trend.

Autoimmune diabetes is commonly assumed to be unrelated to obesity but this assumption might be unjustified in adults because increasing insulin resistance will unmask subclinical beta-cell deficiency regardless of aetiology. Obesity could even promote autoimmunity based on the animal evidence that "stressed" beta cells offer more of a target to the immune system $[108,109]$. This would be consistent with preliminary evidence of an association between GAD antibodies and raised BMI within healthy middleaged people [110,27]. One consequence of the obesity epidemic is that autoimmune diabetes will develop more commonly in overweight people. This combination, whether coincidental or causal, will present the clinician with yet another therapeutic challenge.

The distinction between autoimmune and non-autoimmune diabetes becomes increasingly blurred over the age of 50 years and it is difficult to draw a line between the two with any precision. The requirement for insulin in this age group does however seem similar in either sex. Women live longer and this is a potential cause of bias in studies of the prevalence of Type II diabetes in older people. Once this has been corrected for, no overall sex effect is apparent in later life and sex differences within specific cohorts tend to disappear when correction is made for obesity. It is however worth noting that overweight men and women show an equal and modest decline in insulin sensitivity with increasing age. In contrast, lean females show a rapid decline in insulin sensitivity with age and differ greatly from lean males in this respect [111]. From this observation alone it might be predicted that diabetes would show a female preponderance in later life in lean people, and that the sex ratio would tend to equalise as these people as a whole became more obese.

Our conclusion is that sex effects are present in both Type I and Type II diabetes. These experiments of nature might be telling us something of importance. In 1949 Philip Hench said of spontaneous remission of RA in situations such as pregnancy that "within the patient who has even the severest rheumatoid arthritis powerful corrective forces lie dormant awaiting the proper stimulation" [56]. The challenge in both forms of diabetes is to identify and unlock these corrective forces before the disease has had time to become established.

Acknowledgements. We thank Frans Gorus for helpful comment and criticism of this manuscript.

\section{References}

1. Jacobson DL, Gange SJ, Rose NR, Graham NMH (1997) Epidemiology and estimated population burden of selected autoimmune disease in the United States. Clin Immunol Immunopathol 84: 223-243

2. Beeson PB (1994) Age and sex associations of 40 autoimmune diseases Am J Med 96: 457-462

3. Dorman JS, McCarthy BJ, O'Leary LA, Koehler AN (1995) Risk factors for insulin-dependent diabetes. In: Diabetes in America. 2nd edn. NIH Publication No. 95-1468, pp165-177

4. Risch N, Ghosh S, Todd JA (1993) Statistical evaluation of multiple-locus linkage data in experimental species and its relevance to human studies: application to nonobese diabetic (NOD) mouse and human insulin-dependent diabetes mellitus (IDDM). Am J Hum Genet 53: 702-714

5. Expert Committee on the Diagnosis and Classification of Diabetes Mellitus (1997) Report of the expert committee 
on the diagnosis and classification of diabetes mellitus Diabetes 20: 1183-1197

6. Karjalainen J, Salmela P, Ilonen J, Surcel H-M, Knip M (1989) A comparison of childhood and adult Type I diabetes mellitus. N Engl J Med 320: 881-886

7. Wilson RM, Van der Minne P, Deverill I et al. (1985) Insulin dependence: problems with the classification of 100 consecutive patients. Diabet Med 2: 167-172

8. Tuomi T, Carlsson AL, Li H et al. (1999) Clinical and genetic characteristics of Type II diabetes with and without GAD antibodies. Diabetes 48: 150-157

9. Zimmet PZ, Tuomi T, Mackay IR et al. (1994) Latent autoimmune diabetes in adults (LADA): the role of antibodies to glutamic acid decarboxylase in diagnosis and prediction of insulin dependency. Diabet Med 11: 299-303

10. Molbak AG, Christau B, Marner B, Borch-Johnsen K, Nerup J (1994) Incidence of insulin-dependent diabetes mellitus in age groups over 30 years in Denmark. Diabet Med 11: 650-655

11. Karvonen M, Pitkaniemi M, Pitkaniemi J, Kohtamaki K, Tajima N, Tuomilehto J (1997) Sex differences in the incidence of insulin-dependent diabetes mellitus: an analysis of the recent epidemiological data. Diabetes Metab Rev 13: 275-291

12. Green A, Hauge M, Holm NV, Rasch LL (1981) Epidemiological studies of diabetes mellitus in Denmark. II. A prevalence study based on insulin prescriptions. Diabetologia 20: 468-470

13. Blohme G, Nystrom L, Arnqvist HJ et al. (1992) Male predominance of Type I (insulin-dependent) diabetes mellitus in young adults: results from a 5-year prospective nationwide study in the 15-34 year age group in Sweden. Diabetologia 35: 56-62

14. Bruno G, Pisu E, Merletti F, Giorio M, Vuolo A, Pagano G (1993) Sex differences in incidence of IDDM in agegroup 15-29 years. Higher risk in males in Province of Turin, Italy. Diabetes Care 16: 133-136

15. Roglic G, Pavlic-Renar I, Sestan-Crnek S et al. (1995) Incidence of IDDM during 1988-1992 in Croatia. Diabetologia 38: 550-554

16. Vandewalle C, Shuit FC, Coeckelberghs MI et al. (1997) Epidemiology, clinical aspects, and biology of IDDM patients under age 40 years. Diabetes Care 20: 1556-1561

17. Christau B, Kromann H, Christy M, Andersen OO, Nerup J (1979) Incidence of insulin-dependent diabetes mellitus (0-29 years at onset) in Denmark. Acta Med Scand [Suppl 624]: S 54-60

18. Nystrom L, Dahlquist G, Ostman J, Wall S, Arnqvist HJ, Blohme $\mathrm{G}$ et al. (1992) Risk of developing insulin-dependent diabetes mellitus (IDDM) before 35 years of age: indications of climatological determinants for age at onset. Int J Epidemiol 21: 352-358

19. Allen C, Palta M, D'Alessio DJ (1986) Incidence and differences in urban-rural seasonal variation of Type I (insulin-dependent) diabetes in Wisconsin. Diabetologia 29: 629-633

20. Melton LJ, Palumbo PJ, Chu-Pin C (1983) Incidence of diabetes mellitus by clinical type. Diabetes Care 6: $75-86$

21. Joner G, Sovik O (1991) The incidence of Type I (insulindependent) diabetes mellitus 15-29 years in Norway 1978-82. Diabetologia 34: 271-274

22. Ustvedt HJ, Olsen E (1977) Incidence of diabetes in Oslo, Norway 1956-65. Br J Prev Soc Med 31: 251-257

23. Taha TH, Moussa MAA, Rashid AR, Fenech FF (1983) Diabetes mellitus in Kuwait. Incidence in the first 29 years of life. Diabetologia 25: 306-308
24. Gavard JA, Dorman JS, LaPorte RE et al. (1992) Sex differences in secondary attack rate of IDDM to siblings of probands through older ages. Diabetes Care 15: 559-561

25. Bottazzo GF, Cudworth AG, Moul DJ, Doniach D, Festenstein H (1978) Evidence for a primary autoimmune type of diabetes mellitus. Br Med J ii: 1253-1255

26. Barker DJP, Gardner MJ, Power C (1982) Incidence of diabetes amongst people aged 18-50 years in nine British towns: a collaborative study. Diabetologia 22: 421-425

27. Weets I, Van der Auwera B, Schuit F et al. Male-to-female excess in diabetes presenting after age 15 years: lack of interaction with HLA-DQ, insulin gene polymorphisms or autoimmune markers. Diabetologia 44: 4047

28. Wroblewski M, Fernlund P, Gottsater A, Sundkvist G, Lindgarde F (1998) Sex, autoantibodies, and obesity in newly diagnosed diabetic patients aged $40-75$ years. Diabetes Care 21: 250-255

29. Onkamo P, Vaananen S, Karvonen M, Tuomilehto J (1999) Worldwide increase in incidence of Type I diabetes - the analysis of the data on published incidence trends. Diabetologia 42: 1395-1403

30. Spiegelman M, Marks HH. (1946) Age and sex variations in the prevalence and onset of diabetes mellitus. Am J Public Health 36: 26-33

31. Malins JM, FitzGerald MG, Wall M (1965) A change in the sex incidence of diabetes mellitus. Diabetologia 1: $121-124$

32. Gundersen E (1927) Is diabetes of infectious origin? J Infect Dis 41: 197-202

33. Westlund K (1966) Incidence of diabetes mellitus in Oslo, Norway, 1925 to 1954. Brit J Prev Soc Med 20: 105-116

34. Schuurs AH, Verheul HA (1990) Effects of sex and sex steroids on the immune response. J Steroid Biochem Mol Biol 35: 157-172

35. Ansar Ahmed S, Penhale WJ, Talal N (1985) Sex hormones, immune responses, and autoimmune diseases. Mechanisms of sex hormone action. Am J Pathol 121: $531-551$

36. Lichtman MA, Vaughan JH, Hames CG (1967) The distribution of serum immunoglobulins, anti-gamma-G globulins ("rheumatoid factors") and antinuclear antibodies in white and negro subjects in Evans County, Georgia. Arthritis Rheumatism 10: 204-215

37. Amadori A, Zamarchi R, De Silvestro G et al. (1995) Genetic control of the CD4/CD8 T-cell ratio in humans. Nat Med 1: 1279-1283

38. McEwen BS, Alves SE (1999) Estrogen actions in the central nervous system. Endocr Rev 20: 279-307

39. Gulshan S, McCruden AB, Stimson WH (1990) Oestrogen receptors in macrophages. Scand J Immunol 31: 691-697

40. Gilmore W, Weiner LP, Correale J (1997) Effect of estradiol on cytokine secretion by proteolipid protein-specific $\mathrm{T}$ cell clones isolated from multiple sclerosis patients and normal control subjects. J Immunol 158: 446-451

41. Cohen JH, Daniel L, Cordier G, Saez S, Revillard JP (1983) Sex steroid receptors in peripheral T cells: absence of androgen receptors and restriction of estrogen receptors to OKT8-positive cells. J Immunol 131: 2767-2771

42. Fox HS (1995) Sex steroids and the immune system. Ciba Found Symp 191: 203-211

43. Whitacre CC, Reingold SC, O'Looney PA (1999) A sex gap in autoimmunity. Science 283: 1277-1278

44. Makino S, Kunimoto K, Muraoka Y, Katagiri K (1981) Effect of castration on the appearance of diabetes in NOD mice. Jikken Dobutsu 30: 137-140 
45. Fitzpatrick F, Lepault F, Homo-Delarche F, Bach JF, Dardenne M (1991) Influence of castration,alone or combined with thymectomy, on the development of diabetes in the nonobese diabetic mouse. Endocrinology 29: $1382-1390$

46. Bebo BF, Schuster JC, Vandenbark AA, Offner H (1998) Androgens alter the cytokine profile and reduce encephalitogenicity of myelin-reactive $\mathrm{T}$ cells. J Immunol 162: $35-40$

47. Fox HS (1992) Androgen treatment prevents diabetes in nonobese diabetic mice. J Exp Med 175: 1409-1412

48. Dalal M, Kim S, Voskuhl RR (1997) Testosterone therapy ameliorates experimental autoimmune encephalitis and induces a $\mathrm{T}$ helper 2 bias in the autoantigen-specific $\mathrm{T}$ lymphocyte response. J Immunol 159: 3-6

49. Kelso A (1995) Th1 and Th2 subsets: paradigms lost? Immunol Today 16: 374-379

50. Raghupathy R (1997) Th1-type immunity is incompatible with successful pregnancy. Immunol Today 18: 478-482

51. Morin-Papunen L, Tiilikainen A, Hartikainen-Sorri A-L (1984) Maternal HLA immunization during pregnancy: presence of anti HLA antibodies in half of multigravidous women. Med Biol 62: 323-325

52. Payne R, Rolfs MR (1958) Fetomaternal leukocyte incompatibility. J Clin Invest 37: 1756-1763

53. Tafuri A, Alferink J, Moller P, Hammerling GJ, Arnold B (1995) $\mathrm{T}$ cell awareness of paternal alloantigens during pregnancy. Science 270: 630-633

54. Nelson JL, Hughes KA, Smith AG, Nisperos BB, Branchaud AM, Hansen JA (1993) Maternal-fetal disparity in HLA class II alloantigens and the pregnancy-induced amelioration of rheumatoid arthritis. N Engl J Med 329: 466-471

55. Hench PS (1938) The ameliorating effect of pregnancy on chronic atrophic (infectious rheumatoid) arthritis, fibrositis, and intermittent hydroarthrosis. Proc Mayo Clin Proc 13: $161-168$

56. Hench PS (1949) The potential reversibility of rheumatoid arthritis. Mayo Clinic Proc 24: 167-180

57. Cecere FA, Persellin RH (1981) The interaction of pregnancy and the rheumatic diseases. Clin Rheumatol 7: 747-768

58. Whitaker JN (1998) Effects of pregnancy and delivery on disease activitiy in multiple sclerosis. New Engl J Med 339: 339-341

59. Petri M (1994) Systemic lupus erythematosus and pregnancy. Rheum Dis Clin North Am 20: 87-118

60. Royal College of General Practitioner's Oral Contraception Study (1978) Reduction in incidence of rheumatoid arthritis associated with oral contraceptives. Lancet i: 569-571

61. Spector TD, Roman E, Silman AJ (1990) The pill, parity, and rheumatoid arthritis. Arthritis Rheum 33: 782-789

62. Vandenbroucke JP (1989) Oral contraceptives and the risk of rheumatoid arthritis: the great transatlantic divide? Scand J Rheumatol 79: 31-32

63. Nelson JL, Ostensen M (1997) Pregnancy and rheumatoid arthritis. Rheum Dis Clin North Am 23: 195-212

64. Smith CP, Archibald HR, Thomas JM et al. (1988) Basal and stimulated insulin levels rise with advancing puberty. Clin Endocrinol (Oxf) 28: 7-14

65. Buschard K, Buch I, Molsted-Pedersen L, Hougaard P, Kuhl C (1987) Increased incidence of true type I diabetes acquired during pregnancy. Br Med J 294: 275-279

66. Buschard K, Hougaard P, Molsted-Pedersen L, Kuhl (1990) Type I (insulin-dependent) diabetes mellitus diag- nosed during pregnancy: a clinical and prognostic study. Diabetologia 33: 31-35

67. Hannaford PC, Kay CR (1989) Oral contraceptives and diabetes mellitus. Br Med J 299: 1315-1316

68. Warram JH, Krolewski AS, Gottlieb MS, Kahn CR (1984) Differences in risk of insulin-dependent diabetes in offspring of diabetic mothers and diabetic fathers. N Engl J Med 311: 149-152

69. Warram JH, Krolewski AS, Kahn CR (1988) Determinants of IDDM and perinatal mortality in children of diabetic mothers. Diabetes 37: 1328-1334

70. Warram JH, Martin BC, Krolewski AS (1991) Risk of IDDM in children of diabetic mothers decreases with increasing maternal age at pregnancy. Diabetes 40: $1679-1684$

71. El-Hashimy M, Angelico MC, Martin BC, Krolewski AS, Warram JH (1995) Factors modifying the risk of IDDM in offspring of an IDDM parent. Diabetes 44: 295-299

72. Tuomilehto J, Podar T, Tuomilehto-Wolf E, Virtala E (1995) Evidence for importance of sex and birth cohort for risk of IDDM in offspring of IDDM parents. Diabetologia 38: 982

73. Lorenzen T, Pociot F, Stilgren L et al. (1998) Predictors of IDDM recurrence risk in offspring of Danish IDDM patients. Diabetologia 41: 666-673

74. Yu L, Chase HP, Falorni A, Lernmark A, Eisenbarth GS (1995) Sexual dimorphism in transmission of expression of islet autoantibodies to offspring. Diabetologia 38: $1353-1357$

75. EURODIAB ACE Study Group (1998) Familial risk of Type I diabetes in European children. Diabetologia 41: 1151-1156

76. Helwig EB (1940) Hypertrophy and hyperplasia of islands of Langerhans in infants born of diabetic mothers. Arch Intern Med 65: 221-239

77. Buschard K, Jorgensen M, Aaen K, Bock T, Josefsen K (1990) Prevention of diabetes mellitus in BB rats by neonatal stimulation of $\beta$ cells. Lancet 335: 134-135

78. Bingley PJ, Douek IF, Rogers C, Gale EAM (2000) Influence of maternal age at delivery and birth order on risk of Type I diabetes in childhood: prospective populationbased family study. BMJ (in press)

79. Hales CN, Barker DJP (1993) Type II (non-insulin-dependent) diabetes: the thrifty phenotype hypothesis. Diabetologia 35: 595-601

80. Eaves IA, Bennett ST, Forster P et al. (1999) Transmission ratio distortion at the INS-IGF2 VNTR. Nat Genet 22: $324-325$

81. Bennett ST, Wilson AJ, Esposito L et al. (1997) Insulin VNTR allele-specific effect in Type I diabetes depends upon identity of untransmitted paternal allele. Nat Genet 17: $350-352$

82. Vadheim C, Rotter JI, Maclaren NK, Riley WJ, Anderson CE (1986) Preferential transmission of diabetic alleles within the HLA gene complex. N Engl J Med 315: 1314-1318

83. MacDonald MJ (1987) No evidence for segregation distortion in diabetes. N Eng J Med 316: 1477-1478

84. Lie BA, Ronningen KS, Akselsen HE, Thorsby E, Undlien DE (2000) Application and interpretation of transmission/disequilibrium tests: transmission of HLA-DQ haplotypes to unaffected siblings in 526 families with Type I diabetes. Am J Hum Genet 66: 740-743

85. Becker KB (2000) Comparative genetics of Type I diabetes and autoimmune disease. Common loci, common pathways? Diabetes 48: 1353-1357 
86. Barbesino G, Tomer Y, Concepcion ES, Davies TF, Greenberg DA (1998) Linkage analysis of candidate genes in autoimmune thyroid disease. II. Selected sex-related genes and the X-chromosome. J Clin Endocrinol Metab 98: 3290-3295

87. Cornelis F, Faure S, Martinez M, Prud'homme JF, Fritz P, Dib C (1998) New susceptibility locus for rheumatoid arthritis suggested by genome-wide linkage study. Proc Natl Acad Sci USA 95: 10746-10750

88. Ebers GC, Kukay K, Bulman DE, Sadovnick AD, Rice G, Anderson C (1996) A full genome search in multiple sclerosis. Nat Genet 13: 472-476

89. Sundvall M, Jirholt J, Yang HT et al. (1995) Identification of murine loci associated with susceptibility to chronic experimental autoimmune encephalitis. Nat Genet 10: 313-317.

90. Cucca F, Goy JV, Kawaguchi Y et al. (1998) A male-female bias in Type I diabetes and linkage to chromosome $\mathrm{Xp}$ in MHC HLA-DR3-positive patients. Nat Genet 19: 301-302

91. Naumova AK, Leppert M, Barker DF, Morgan K, Sapienza C (1998) Parental origin-dependent, male offspringspecific transmission-ratio distortion at loci on the human X chromosome. Am J Hum Genet 62: 1493-1499

92. Zavattari P, Esposito L, Nutland S, Todd JA, Cucca F (2000) Transmission-ratio distortion at Xp11.4-p21 in Type I Diabetes. Am J Hum Genet 66: 330-332

93. King H, Rewers M, WHO ad hoc Diabetes Reporting Group (1993) Global estimates for prevalence of diabetes mellitus and impaired glucose tolerance in adults. Diabetes Care 16: 157-177.

94. Pincus G, Joslin EP, White P (1934) Age-incidence relations in diabetes mellitus. Am J Med Sci 188: 116-121

95. Harris H, MacArthur N (1951) Changes in sex incidence of diabetes mellitus (1912-1947). Ann Eugen 16: 109-118.

96. Tull ES, Roseman JM (1995) Diabetes in African Americans. Chapter in: Diabetes in America. 2nd edn. NIH Publication No. 95-1468, pp613-630

97. West KM (1978) Epidemiology of diabetes and its vascular lesions. New York: Elsevier

98. Kuczmarski RJ et al. (1994) Increasing prevalence of overweight among US adults. The National Health and Nutrition Examination Surveys 1960 to 1991. J Am Med Assoc 272: 205-211
99. Midthjell K, Claudi T, Kruger O, Bjorndal A, Holmen J, Magnus P, Tverdal A (1999) Rapid changes in the prevalence of obesity and known diabetes in an adult Norwegian population. The Nord-Trøndelag Health Surveys: 1984-86 and 1995-97. Diabetes Care 22: 1813-20

100. Riley MD, Blizzard CL, McCarty DJ, Senator GB, Dwyer T, Zimmet P (1996) Parental history of diabetes in an insulin-treated diabetes registry. Diabetic Med 14: 35-41

101. O'Rahilly S, Spivey RS, Holman RR, Nugent Z, Clark A, Turner RC (1987) Type II diabetes of early onset: a distinct clinical and genetic syndrome? Brit Med J 294: 923-928.

102. Yki-Jarvinen H (1984) Sex and insulin sensitivity. Metabolism 33: 1011-1015

103. Nuutila P, Knuuti J, Maki M et al. (1995) Sex and insulin sensitivity in the heart and skeletal muscles. Studies using positron emission tomography. Diabetes 44: 31-36

104. Donahue RP, Goldberg RB, Bean JA, Prineas RJ, Donahue RA (1997) Insulin response in a triethnic population: effects of sex, ethnic origin, and body fat. Diabetes Care 20: $1670-1676$

105. Willett WC, Dietz WH, Colditz GA (1999) Guidelines for healthy weight. N Engl J Med 341: 427-433

106. Horber FF, Gruber B, Thomi F, Jensen EX, Jaeger P (1997) Effect of sex and age on bone mass, body composition and fuel metabolism in humans. Nutrition 13: $524-534$

107. Samaras K, Campbell LV (2000). Increasing incidence of Type II diabetes in the third millenium. Is abdominal fat the central issue? Diabetes Care 23: 441-442

108. Aaen K, Rygaard J, Josefsen K et al. (1990) Dependence of antigen expression on functional state of $\beta$-cells. Diabetes 39: 697-701

109. Bjork E, Kampe O, Andersson A, Karlsson FA (1992) Expression of the $64 \mathrm{kDa}$ /glutamic acid decarboxylase rat islet cell autoantigen is influenced by the rate of insulin secretion. Diabetologia 32: 490-493

110. Rolandsson O, Hagg E, Hampe C, Sullivan EP, Nilsson M, Jansson G, Hallmans G, Lernmark A (1999) Glutamate decarboxylase (GAD65) and tyrosine-phosphatase-like protein (IA-2) autoantibodies index in a regional population is related to glucose intolerance and body mass index. Diabetologia 42: 555-559

111. Ferranini E, Vichi S, Beck-Nielsen H et al. (1996) Insulin action and age. Diabetes 45: 947-953 